\title{
The importance of cassava in world food production
}

\author{
G. H. DE BRUIJN \& L. O. FRESCO \\ Department of Tropical Crop Science, Agricultural University Wageningen, P.O. Box 341, \\ NL 6700 AH Wageningen, Netherlands
}

Received 29 June 1988; accepted 25 November 1988

\begin{abstract}
This article examines the validity of the assumption that the importance of cassava in expanding food production in developing countries is increasing. Trends in production, area and yield of nine staple crops, in view of population growth, are compared for a 22-year period, and changes in the relative importances of crops are discussed. Cassava, like other roots and tubers, with the exception of potato, is losing importance on a global scale. In Africa, cassava production has lagged behind population growth, and this reflects in fact the general relative decline in per capita food availability. A more detailed analysis of cassava and maize, its ecological alternative, for selected African countries confirms the general trend that the relative growth of cassava production has been lower than that of maize. Country level deviations as well as agronomic implications are discussed.
\end{abstract}

Keywords: Africa, cassava, developing countries, food crop production

\section{Introduction}

According to FAO statistics (1987) on an energy production basis, cassava ranks fourth on the list of major food crops in developing countries, after rice, wheat and maize. It is an important food crop for some 500 million people; in some countries, cassava provides over $50 \%$ of the average daily caloric intake (Cock, 1985). Table 1 shows the most important cassava-producing countries of the world.

Until recently, cassava was almost ignored by researchers and policy makers; however, in the last 15 years there has been a world-wide surge in interest in the potentials of this crop. There are several reasons for cassava playing an important role in world food supply, and for hypothesizing that its importance could be increasing.

Firstly, the crop is known as a relatively efficient producer even under adverse conditions, like erratic and low rainfall and low soil fertility. In shifting cultivation, and other fallow systems, cassava is often used as the last crop in the cropping cycle. Rapid population growth in many developing countries leads to an expansion of arable land areas, the increase often being realized by shortening the fallow period in rotation systems or by exploiting marginal land with low soil fertility and/or low rainfall. Thus, because of the crop's ability to produce under marginal conditions 
Table 1. Main cassava-producing countries in 1986 (source: FAO Production Yearbook, 1987).

\begin{tabular}{lcc}
\hline & $\begin{array}{l}\text { Total production } \\
\left(\times 10^{6} \mathrm{Mt}\right)\end{array}$ & $\begin{array}{l}\text { Percentage of } \\
\text { world production }\end{array}$ \\
Brasil & 25.5 & 18.6 \\
Zaire & 15.6 & 11.4 \\
Thailand & 15.3 & 11.1 \\
Nigeria & 14.7 & 10.7 \\
Indonesia & 13.3 & 9.7 \\
India & 6.0 & 4.4 \\
Tanzania & 5.5 & 4.0 \\
Uganda & 5.0 & 3.6 \\
Ghana & 3.7 & 2.7 \\
China & 3.6 & 2.6 \\
Mozambique & 3.3 & 2.4 \\
Vietnam & 3.0 & 2.2 \\
Paraguay & 2.9 & 2.1 \\
Madagascar & 2.4 & 1.7 \\
Others & 17.6 & 12.8 \\
& & \\
World & 137.4 & \\
\hline
\end{tabular}

one could hypothesize that its role may become more important in areas where increased food production is attainded mainly by taking more marginal land into production.

Another possible reason for an increased importance of cassava is to be sought in a higher efficiency of energy production (like that for other root and tuber crops) as compared to cereal crops, mainly because of a more favourable dry matter distribution. The harvest index of root and tuber crops is much higher than that of cereal crops (de Vries et al., 1967). Furthermore, cassava production requires less labour per calorie harvested than some other staple food crops, and, more importantly, it allows a great degree of flexibility in the timing of labour inputs - a fact which is of special importance to women (Okali \& Berry, 1985). In areas where male outmigration leads to labour shortages and to a 'feminization' of agriculture, a shift to cassava could solve some of the problems in food supply.

In this article, an attempt is made to investigate the existence of a possible trend towards a relative increase in the contribution of cassava to an expanding world food production. Data from FAO statistics over the period 1961-1986 were studied for this purpose (FAO, 1973, 1976, 1982, 1984, 1987). It is recognized that national production statistics in some developing countries may be subject to error, but their use seems justified in studying long-term relative trends. On the one hand, cassava is compared with other important root and tuber crops, i.e. yam, sweet potato and potato, and on the other hand a comparison is made with cereals, i.e. rice, wheat, maize, sorghum and millet. Minor starchy staples were not taken into consideration. The crop production data are then compared with those on population growth. 
In first instance, this analysis was carried out for Africa, Latin America and the Far East. An overall picture of developing countries with a market economy, thus excluding China, is also given. Secondly, a more detailed analysis was undertaken of selected countries in Africa. For this purpose, cassava is compared to maize, a crop which can be considered as an alternative to cassava under various ecological conditions.

\section{Production trends in nine major annual food crops in the tropics}

\section{General}

Table 2 presents data on area, yield and total production for the years 1961/65, $1974 / 76$ and 1984/86 for cassava, potato, yam, sweet potato, rice, wheat, maize, sorghum and millet, grown in developing countries with a market economy in Africa, Latin America, the Far East and the total of developing countries (thus also including the Near East, Central America, etc.). The table includes data on human population over the three periods, for the years 1963, 1975 and 1985 and information on increases or decreases, between 1961/65 and 1984/86 (i.e. 22 years), expressed as percentages of the 1961/65 data. The table also presents the ratios of relative growth of commodities over 22 years versus relative growth of population in that period.

Table 3 summarizes the trends for relative growth in production based on the ratios from Table 2. It indicates in which cases, and to which extent, production growth of the nine commodities has kept pace with human population increase. Assuming no interference from changes in consumer preferences or imports/exports of food, one would expect a perfect matching of population growth and production increase. However, with a few exceptions this was not observed.

The general picture for cassava shows a relative decrease in Africa, a very important relative decrease in Latin America and an important relative increase in the Far East. On the whole, cassava production increase lags slightly behind population increase $(67 \%$ compared to $71 \%)$. However, if Thailand, where cassava is produced only for export and mainly for animal feed, would be excluded, the increase for the Far East would be eliminated. Thus the general conclusion can be that in the period 1961/65 to $1984 / 86$, total cassava production for human consumption did not increase as much as human population. On a global scale, the role of cassava in human nutrition became slightly less important in that period.

Considering the other commodities in a similar way, one observes a general decrease in relative importance of sweet potato and millet, and a slight overall increase in relative importance of maize (China, not included in these statistics, but producing more than $80 \%$ of the world production of sweet potato, shows a similar decline in the importance of this crop). A remarkable development is the strong increase in importance of potato in Africa and the Far East; total production has tripled in the period considered. In Latin America, however, the increase in potato production does not keep up with the increase in population. For yam, we see a relative decrease in importance in Africa. The importance of sorghum decreases in 
G. H. DE BRUIJN AND L. O. FRESCO

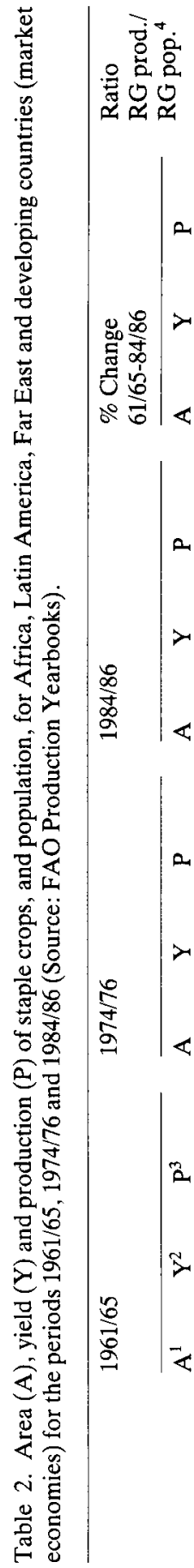

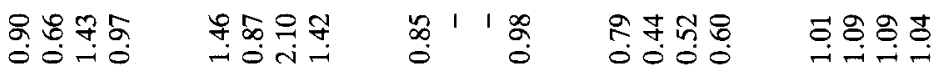

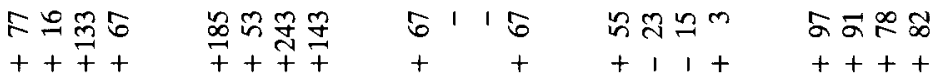

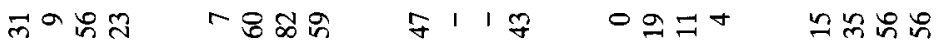

$+1+++++++++1+1+++$

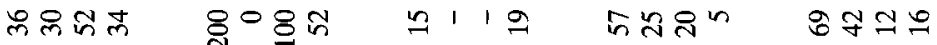

$++++\underset{+}{+}+++11+++++$

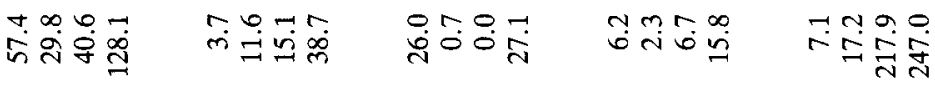

뤁워

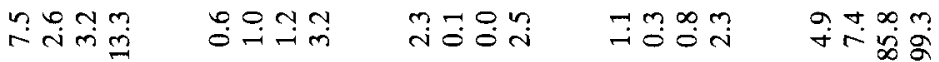

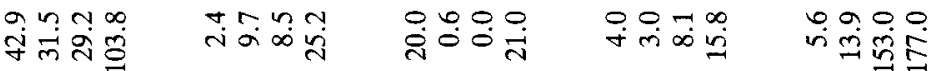

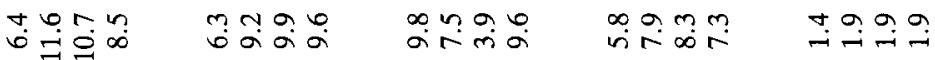

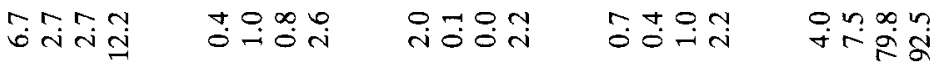

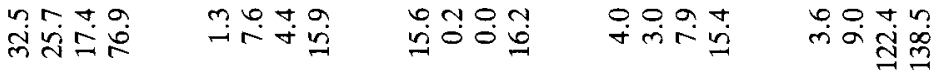

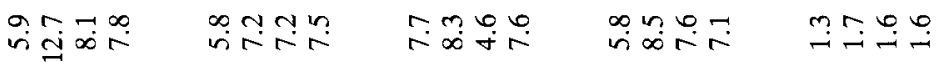

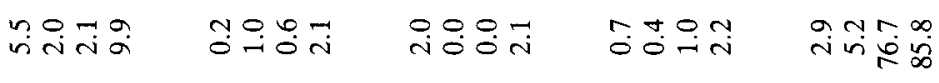

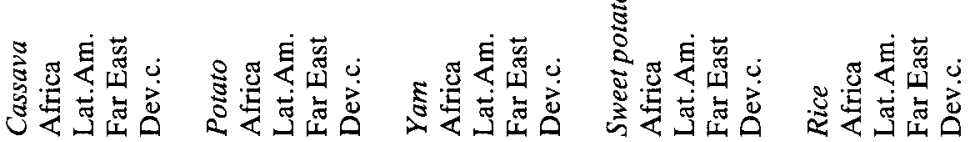

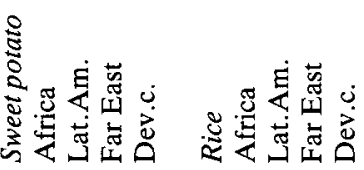




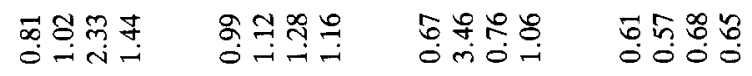

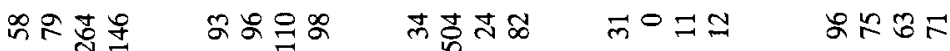

$++7+++++++++++++++$

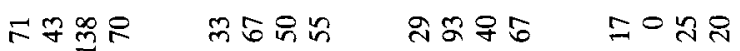

$++t++++++++++++$

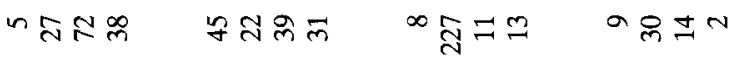

$1++++++++1++111$

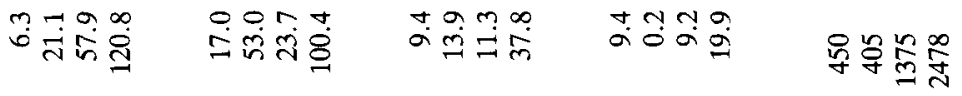

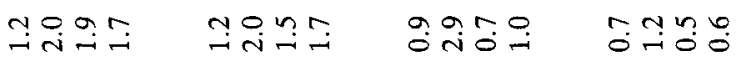

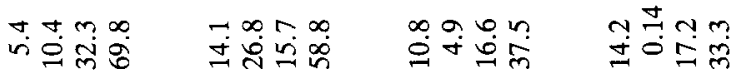

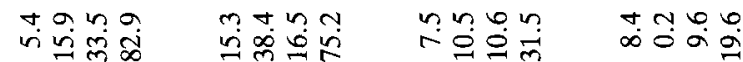

m대용

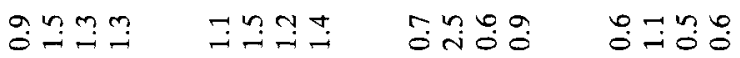

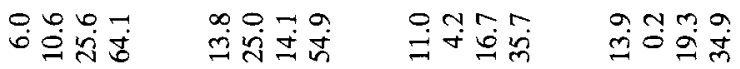

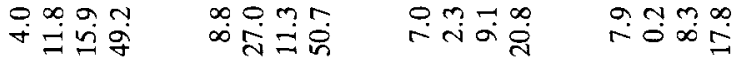

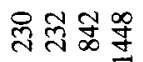

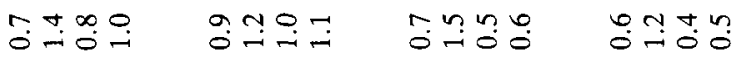

부ㅇㅛㅛ

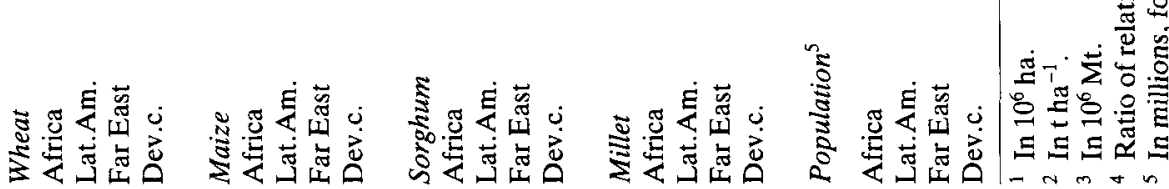


Table 3. Simplified presentation of the ratio' $\mathrm{s}^{1}$ of relative growth of production of staple crops and relative growth of population by continent, from 1961/65 to 1984/86.

\begin{tabular}{lrrrr}
\hline & Africa & Latin America & Far east & Dev. countries ${ }^{2}$ \\
Cassava & & -- & +++ & 0 \\
Potato & +++ & - & +++ & +++ \\
Yam & - & -- & -- & 0 \\
Sweet potato & -- & + & + & 0 \\
Rice & 0 & 0 & +++ & +++ \\
Wheat & -- & + & ++ & ++ \\
Maize & 0 & +++ & -- & + \\
Sorghun & --- & --- & -- & -- \\
Millet & --- & & & + \\
\hline
\end{tabular}

${ }^{1}$ See Table 2:

$\begin{array}{rrrrr}0 & : \text { deviation from } 1.00 \text { is } & 0 & -0.05 \text { (plus or min) } \\ + \text { or }- & : & " & 0.05-0.15 & " \\ ++ \text { or }-- & : & " & 0.16-0.30 & " \\ +++ \text { or }---: & ", & \geqslant 0.30\end{array}$

${ }^{2}$ Market economies.

Africa and the Far East, but increases in Latin America, probably because of its growing importance there as an animal feed.

A more refined analysis can be made when the relative importance of the various crops in the periods 1961/65 and 1984/86 are compared on a dry matter basis (conversions according to Platt, 1971). The results are presented in Table 4. In Africa, major increases in relative importance are found for maize, rice and potato and major decreases for millet and sorghum. In Latin America there is a striking increase for sorghum, while most important decreases are found for cassava, potato, sweet potato and millet. The Far East shows an important increase for wheat, cassava, maize and potato, and a decrease for rice, millet and sorghum. The overall picture of all developing countries shows important increases for wheat and potato and decreases for millet, cassava and sweet potato.

When developing countries are considered as a group, root and tuber crops show relative decreases in production. In 1961/65 they represented $15.0 \%$ of total production of the nine crops and in 1984/86 $13.3 \%$, thus a relative decline of $13 \%$. However, this trend does not hold true for potato. The relative importance of potato increased by $0.3 \%$, but the overall importance of this crop only covers $1.4 \%$ of total dry matter of the nine crops considered.

One more aspect should be mentioned. If one compares the production growth of all nine crops, it appears that in Africa the production increase (64\%) is markedly lower than the population increase (96\%), whereas in Latin America and the Far East, production increases markedly surpass population increases (Latin America $89 \%$ vs $75 \%$, Far East $93 \%$ vs $63 \%$ ). The importance of imports and exports have not been taken into account in these figures. However, it is evident that the per capita food availability in Africa has decreased dramatically. 


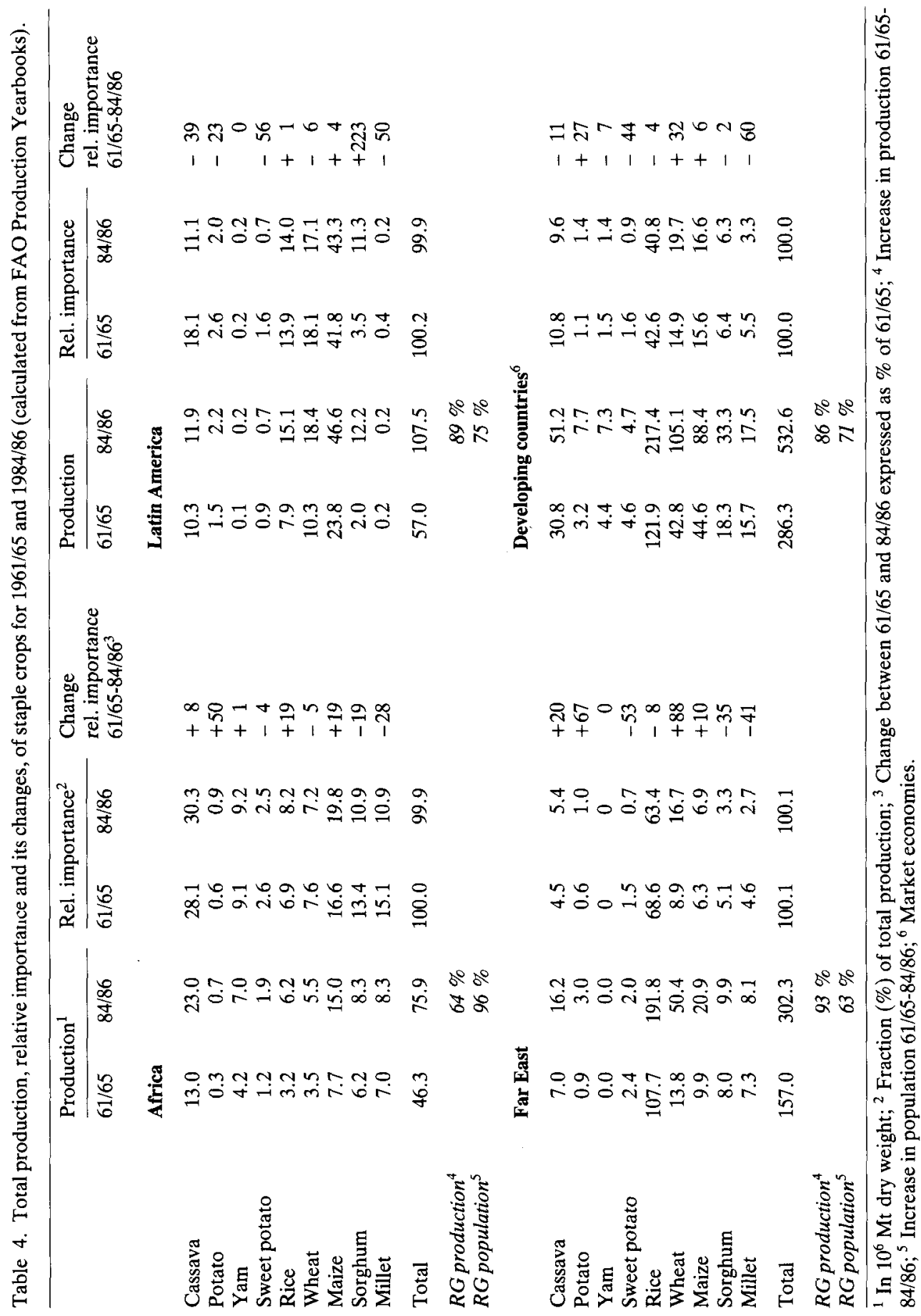

Netherlands Journal of Agricultural Science 37 (1989) 


\section{Relative production trends in cassava}

The production data for cassava (Table 4) and ecologically alternative crops - the tuber crops yam and sweet potato and the cereals maize, sorghum and millet - show no evidence to support the idea that the relative position of cassava has become more important since 1961/65. On the contrary, the general trend is that cassava, like yam and sweet potato is loosing ground, with Africa and the Far East as possible exceptions. However, as mentioned before, the relative increase in the Far East does not indicate a more important role for cassava in the human diet. The slight relative increase in Africa must be interpreted with caution, because in reality there is an overall decline in food availability (Table 2). Total cassava production in Africa has grown by $77 \%$, as compared with a $96 \%$ population increase. The small increase in the relative importance of cassava (from 28.1 to $30.3 \%$ ) indicates that the overall relative decline in food production in Africa has been somewhat less for cassava than for the average of the combined commodities (total production of the nine crops has only risen $64 \%$ ).

In summary, one is led to the conclusion that the available FAO statistics (which are the only long-term sources of data) do not offer any evidence to support the hypothesis of a relative increase in importance of cassava in world food supply. On the contrary, a small relative decrease may be observed. Furthermore, of all ecologically alternative crops, the only one that has strengthened its position in comparison to cassava across all continents, is maize. These aggregated continental statistics do not allow one to conclude, however, that maize has replaced cassava in Africa and elsewhere. In order to shed more light on the relative importance of cassava and maize, and on possible substitution effects, national production figures of selected African countries will be discussed below.

\section{Production trends in cassava and maize in selected African countries}

\section{General}

African countries can be divided into three categories, following the grouping suggested by FAO on the basis of cassava consumption patterns (FAO, 1986). Group 1 comprises countries with production and consumption dominated by cassava accounting for over $50 \%$ of staple food calories (Central African Republic (CAR), Congo, Mozambique and Zaire). In the countries of group 2, roots, tubers and plantains provide approximately $50 \%$ of the staple diet, while cereals provide the other half (Angola, Benin, Burundi, Cameroun, Comoros, Equatorial Guinea, Gabon, Ghana, Ivory Coast, Nigeria, Rwanda, Tanzania, Togo and Uganda). In this group, cassava is much less important than in group 1 . In the remaining countries, group 3, cereals dominate production and consumption, although cassava may be of local importance.

Table 5 presents data for three countries from each group, including the largest three African cassava producers Zaire, Nigeria and Tanzania. 


\section{Production trends in cassava}

The data in Table 5 suggest some country level deviations from the general African trend of a relative decline in cassava production as compared to population growth (Table 2). While the overall figures for cassava in Africa suggest that yield and area increase have more or less kept the same pace, this is by no means the case for individual countries. Only in three countries (Zaire, Ghana and Madagascar) has cassava production been able to keep pace with population growth. In two other countries depending heavily on cassava (CAR and Congo), even absolute production has decreased. Madagascar has been the only country with production growth of cassava surpassing that of maize. The figures for Tanzania are internally inconsistent, so that not much weight can be attached to them. If Tanzania and the countries with cassava production decreasing or remaining constant (Bourkina Faso) are disregarded, all other countries show a production growth resulting from increases in area rather than from increases in yield. In Zaire, production growth has in fact been accomplished solely through area expansion notwithstanding declining yields. This trend is confirmed by a detailed longitudinal study of cassava yields in the South West of Zaire (Fresco, 1986). Except Nigeria and Ghana, all other African countries show yields below the continent's average of 7.7 ton ha ${ }^{-1}$ (1984-1986). In the countries of group 1 (high cassava consumption), the situation seems most serious: declining production and area in Congo and the CAR, yield decreases in Zaire and the CAR.

\section{Production trends in maize}

With the exception of the CAR, Nigeria, Bourkina Faso and Madagascar, the increase in maize production has been more important than population growth. In Tanzania, Congo and Zaire, maize production has more than doubled during the 22-year period considered, although in the latter two countries there has been no increase in yield, or even a slight decline. As in the other countries, with the noticeable exception of Nigeria and Bourkina Faso, most production growth in maize can be explained by area expansion. The relatively high Nigerian maize yields, over 2 ton $\mathrm{ha}^{-1}$, reflect the successful introduction of improved (hybrid) varieties and fertilizer during the last decade (in contrast to Zambia, where maize yields were already high in the early 1960's and have hardly increased since).

In group 3 (cereal-dominated diet), maize yields have increased slightly or not at all, with the exception of Bourkina Faso, while in group 1 (cassava-dominated diet) yields have declined everywhere. Only in the countries of group 2, maize production increase has been based partly on raised yields.

In all countries of Table 5, however, total maize production represents only onethird of total cassava production on a dry weight basis ( 5 million ton vs over 15 million ton, respectively, in 1984/86, compared to 2 and 8 million ton, respectively, in $1961 / 65)$. Thus, the relative importance of maize increased by about $25 \%$. On a continental basis, the maize-to-cassava ratio is two to three, and the increase in relative importance of maize in total food production was $19 \%$ (Table 4). 
G. H. DE BRUIJN AND L. O. FRESCO

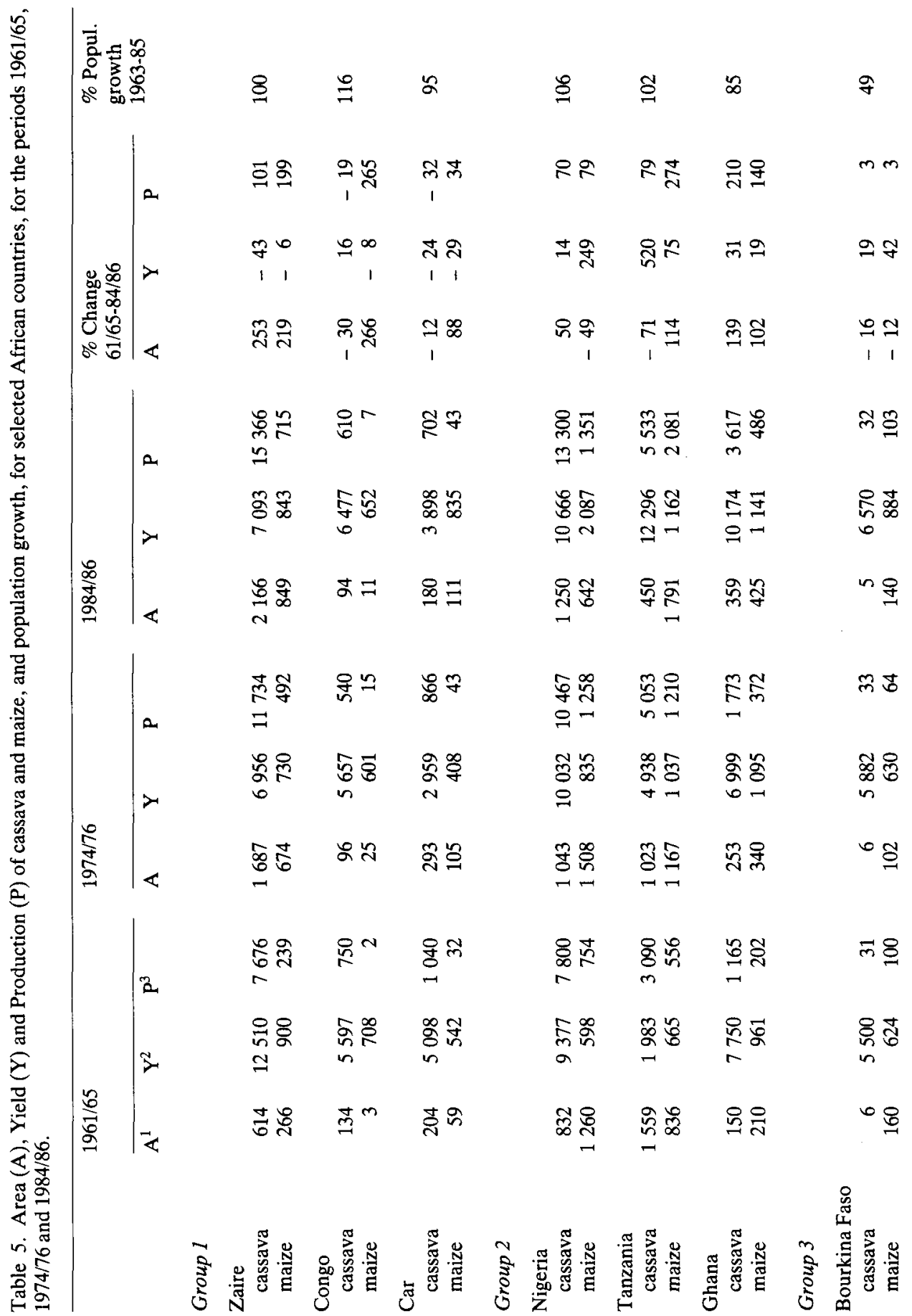


$8+\frac{1}{8}$

F严栗导

아 $\rightarrow$ 음

흠워

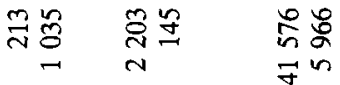

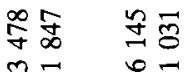

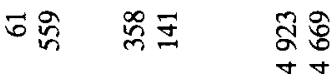

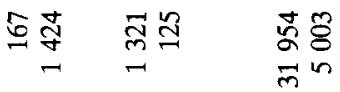

규요 웜

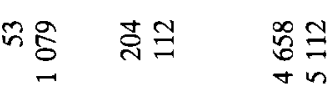

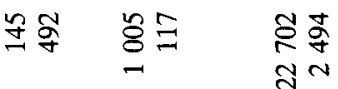

도용

$\rightarrow \rightarrow 0-1$

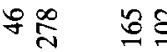

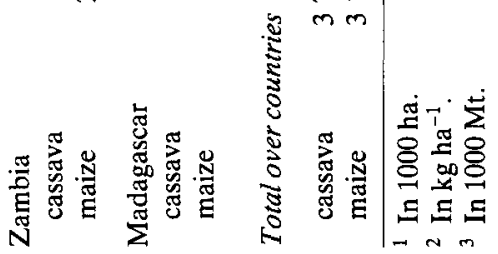




\section{Discussion}

\section{Validity of data}

The use of individual country data may be more hazardous than that of aggregated data (Paulino, 1987). Official government statistics may yield a distorted image of reality because either farmers or governments benefit from underreporting (Berry, pers. comm.) or because of poor data collection and analysis. Whatever the reasons, African data display disturbing gaps and contradictions (Eurostat, 1986), either because various national sources produce different results for the same year or because provincial or district data are inconsistent with national statistics.

For cassava, these overall statistical problems are aggravated by the special nature of the crop. Most cassava is probably grown by women for domestic consumption with irregular supplies to local markets, thus rendering the crop nearly invisible in national statistics. Cultural practices, such as staggered planting and harvesting, intercropping and widely varying planting densities, as well as the fact that the actual amount harvested (and therefore yield) is a function of household consumption, cash needs and labour availability, make yield and area estimates dubious at least (Fresco, 1986). Since cassave is hardly ever marketed as a fresh product, the conversion of roots to marketable produce may present problems. The low yield values for Tanzania in 1961/65 and the rapid increase thereafter might be attributed to this fact which is also alluded to by FAO (1976).

Maize statistics are less likely subjected to such measuring errors, because nearly the whole crop is harvested at the same time and because in many countries specialized agencies for maize promotion and marketing exist (although conversion errors due to variations in shelling percentage might occur).

\section{Maize versus cassava}

On the demand side, two factors may explain the growing relative importance of maize in Africa: consumer preferences for cereals in general and the demand for products that can easily be harvested, transported, processed and stored. Both factors reflect the growing urbanization in Africa. However, they do not fully account for the shift towards maize. Income elasticity of cassava is positive, even if low, and is generally higher in urban areas than in rural communities (Phillips, 1983). Cassava products, such as gari and lagun in Nigeria or cossettes in Zaire, are easily stored and transported, but require high labour inputs. Processing of gari in Nigeria is increasingly becoming mechanized, so that in this respect the comparative advantages of maize for consumers are reduced. Relative price levels may favour maize, especially in countries with national maize promotion programmes. Cassava is often in a disadvantage in comparison with cheap imported cereals such as wheat and rice, so that it has perhaps acquired the reputation of an 'expensive' food - a fact which might even promote its consumption by the urban elite.

On the supply side, maize has benefited more from the supply of subsidized fertilizers than has cassava, which is not only rarely fertilized but often grown under 
marginal fertility conditions on depleted soils. Furthermore, a greater amount of agronomic research has been carried out on maize. Thus, it comes as no surprise that the increase in the relative importance of maize surpasses that of cassava. Since 1961/65, maize yields in developing countries (market economies) have risen $55 \%$ and cassava yields $23 \%$ (Table 2 ).

The incidence of pests and diseases in cassava, in particular mealy bug and bacterial blight, might explain a producer preference for maize, although in Zaire, yield declines in cassave were already apparent long before the spread of these pathogens (Fresco, 1986). The lack of healthy plant material could have prevented an expansion of cassava growing in some cases, but the observed overall increase in area does not warrant such an assumption. Nevertheless, pests and diseases may seriously affect the future balance between cassava and maize, although striga could also become a problem for the expansion of maize in savanna regions.

The growing overall importance of maize, however, does not necessarily imply a replacement of cassava by maize. In fact, one could visualize traditional crops such as sorghum, millet and yam being replaced by both maize and cassava, but at different rates. Where ecological and market conditions are most favourable, maize rather than cassava will likely be the preferred crop. In countries where cassava production has not kept up with population growth, it might have been replaced by either maize or imported cereals, or per capita consumption of cassava and food availability simply might have declined.

\section{Future role of cassava in expanding food production}

The foregoing analysis suggests that, on a world-wide scale, cassava is becoming relatively less important, both on a per capita basis and in its contribution to total food production. With some exceptions, this also seems to apply to Africa. At the same time the importance of maize is expected to grow. This pattern reflects the overall balance between roots and tubers on the one hand and cereals on the other. With the noticeable exception of potato, the importance of roots and tubers in total food production and on a per capita basis is declining.

This conclusion contradicts the hypothesis of a growing role of cassava in expanding food production. Some possible explanations have been given in the previous section, with particular reference to Africa. The agronomic implications are discussed below.

If cassava growing is not expanding as rapidly as expected, this might mean that the deterioration of soil fertility has not yet reached a point at which only cassava produces acceptable yields. Declining yields or stagnating yield increases in several regions of the African continent suggest, however, that this point is being approached. Since cassava is usually grown as the last crop in the rotation before fallow, the cassava area expansion in most countries, specificly in Zaire, Ghana and Madagascar, provides indirect evidence for the widely heard claim that fallows are shortening and land is used more intensively. Where most production growth has resulted from area expansion, a heavy burden is placed on farmers, whether the area expansion comes from new land brought under cultivation or from a shorten- 
ing of the fallow. The expansion of cassava area forms a strong justification for any efforts to intensify production through increased outputs per unit of land and increased labour inputs. However, so far average world yield levels have remained low.

Notwithstanding low yields, even where the absence of rapidly deteriorating conditions do not force farmers to grow cassava, the crop may present some real advantages. For instance, it allows great flexibility in planting and harvesting strategies and enables farmers to respond to rapid changes in the physical, biological and socio-economic environment. Variations in the official statistics may, among other things, also reflect this variability in farmer response. Cassava may remain important for subsistence needs and as an intermittent source of cash, even if other crops such as maize are dominant. Nearly the whole crop is produced today in a labour-intensive way with little or no external inputs (with the exception of Thailand). This pattern may change as more commercialized production systems emerge, e.g. in urban peripheries, where smallholder production may expand rapidly. In heavily urbanized Oyo State (Nigeria), for example, average cassava production per household grew $230 \%$ during 1980-1985 (Ikpi et al., 1986). A more complete understanding is needed of the penetration of cassave into non-traditional growing areas outside the Sudano-Guinean Zone. Thus, two types of cassava farmers may be emerging: the subsistence-oriented and the market-oriented producers. Agricultural research institutes may need to focus their work more clearly on the specific needs and potential of each of these groups.

\section{References}

Cock, J. H., 1985. Cassava. New potential for a neglected crop. IADS/Westview Press, Boulder Colorado, $192 \mathrm{pp}$.

Eurostat, 1986. Statistics in support of African food strategies and policies. The Courier 99: 59-61.

FAO, 1973, 1976, 1982, 1984, 1987. Production Yearbooks. Volumes 26, 29, 35, 37 and 40. FAO, Rome.

FAO, 1986. The role of roots, tubers and plantains in food security in sub-Saharan Africa. Committee on World Food Security, Eleventh Session, Rome, $21 \mathrm{pp}$.

Fresco, L. O., 1986. Cassava in shifting cultivation. A systems approach to agricultural development in Africa. Royal Tropical Institute, Amsterdam, $244 \mathrm{pp}$.

Ikpi, A., T. Gebremeskel, N. Hahn, H. Ezumah \& J. Ekpere, 1986. Cassava - a crop for household food security. A 1986 situation analysis for Oyo Local Government Area - Nigeria. ITTA - Unicef Collaboration Program, IITA Ibadan, $113 \mathrm{pp}$.

Okali, C. \& S. Berry, 1985. Alley farming in West Africa in comparative perspective. Boston University, African-American Issues Center. Working Paper No 11.

Paulino, L. A., 1987. The evolving food situation. In: J. W. Mellor, C. L. Delgado \& M. J. Blackie (Eds), Accelerating food production in sub-Saharan Africa, p. 23-28. Johns Hopkins University Press, Baltimore.

Phillips, T. P., 1983. An overview of cassava consumption and production. In: F. Delange \& R. Ahluwalia (Eds), Cassava toxicity and thyroid: research and public health issues, p. 83-88. Workshop Proceedings. IDRC-207e, IDRC, Ottawa.

Platt, B. S., 1971. Tables of representative values of foods commonly used in tropical countries. Medical Research Council Special Report Series No 302. Her Majesty's Stationery Office, London.

Vries, C. A. de, J. D. Ferwerda \& M. Flach, 1967. Choice of food crops in relation to actual and potential production in the tropics. Netherlands Journal of Agricultural Science 15: 241-248. 